\title{
Scutebarbatines W-Z, New neo-Clerodane Diterpenoids from Scutellaria barbata and Structure Revision of a Series of 13-Spiro neo-Clerodanes
}

\author{
Fei WAnG, ${ }^{*, a, b}$ Fu-Cai Ren, ${ }^{b}$ Ya-Ju Li, ${ }^{b}$ and Ji-Kai Liu ${ }^{*, a}$ \\ ${ }^{a}$ State Key Laboratory of Phytochemistry and Plant Resources in West China, Kunming Institute of Botany, Chinese \\ Academy of Sciences; Kunming 650204, China: and ${ }^{b}$ BioBioPha Co., Ltd.; Kunming 650204, China. \\ Received June 1, 2010; accepted June 18, 2010; published online June 23, 2010
}

\begin{abstract}
Four new neo-clerodane diterpenoids, scutebarbatines $\mathrm{W}-\mathrm{Z}(1-4)$, were isolated from the ethanol extract of Scutellaria barbata (Labiatae), and their structures were elucidated on the basis of extensive spectroscopic studies. In addition, the proposed structures of at least seven 13-spiro subtype neo-clerodanes: scutehenanine B (5), scutebarbatine G (6), 6-O-nicotinoylscutebarbatine G (7), barbatin A (8), 6,7-di- $O$-nicotinoylscutebarbatine G (9), 6- $O$-nicotinoyl-7- $O$-acetylscutebarbatine $G$ (10), and scutebarbatine F (11), reported by Dai and co-workers from the same species, were incorrectly assigned and have been revised by reanalysis of the published NMR data.
\end{abstract}

Key words Scutellaria barbata; neo-clerodane diterpenoid; structure revision

Species of the genus Scutellaria (family Labiatae) are deemed as the source of the most potent neo-clerodane insect antifeedants known so far, and over 150 neo-clerodane diterpenoids have been isolated from this genus, which makes them potentially useful as ecologically acceptable agents for pest control. ${ }^{1)}$ Recently, a series of cytotoxic neo-clerodanes were reported from Scutellaria barbata-a traditional Chinese herbal medicine named "Ban Zhi Lian."2-14) As part of BioBioPha to assemble a large-scale natural compound library which is very valuable in the discovery of new lead compounds from nature, ${ }^{15-19)}$ further chemical investigation on $S$. barbata afforded four new neo-clerodane derivatives, scutebarbatines $\mathrm{W}-\mathrm{Z}(\mathbf{1}-\mathbf{4})$ (Fig. 1), along with nine known neo-clerodanes, scutebatas $\mathrm{A}-\mathrm{C},{ }^{13)}$ scutebatas $\mathrm{E}-$ $\mathrm{G},{ }^{11,13)}$ scutebarbatines $\mathrm{A}$ and $\mathrm{B}^{2,4)}$ and 6-O-nicotinoylbarbatin $\mathrm{C}^{6)}$ Furthermore, the structures of at least following seven 13-spiro neo-clerodanes: scutehenanine B (5), ${ }^{10)}$ scutebarbatine $\mathrm{G}(6),{ }^{5}$ 6-O-nicotinoylscutebarbatine $\left.\mathrm{G}(7),{ }^{9}\right)$ barbatin A (8), ${ }^{4)}$ 6,7-di- $O$-nicotinoylscutebarbatine $\mathrm{G}(9),{ }^{5)} 6-O$ nicotinoyl-7- $O$-acetylscutebarbatine $\mathrm{G}(\mathbf{1 0}),{ }^{5)}$ and scutebarbatine F (11), ${ }^{3)}$ continuously reported by Dai and co-workers from the same plant, were incorrectly assigned and have been revised. Herein, we report the structure elucidation of new compounds as well as structure revision of some analogues.

\section{Results and Discussion}

Compound 1, obtained as amorphous powder, had a molecular formula of $\mathrm{C}_{33} \mathrm{H}_{37} \mathrm{NO}_{8}$ based on the positive high resolution-electrospray ionization (HR-ESI)-MS, showing a quasi-molecular ion peak at $m / z 598.2426$ (Calcd for

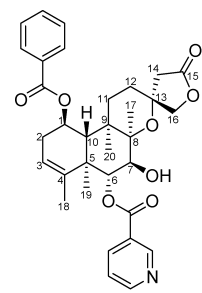

1

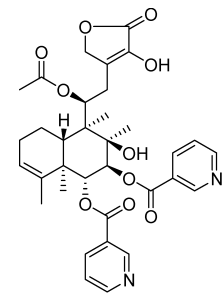

2

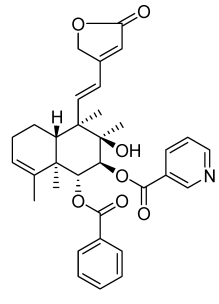

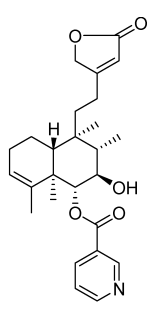

Fig. 1. Structures of Scutebarbatines $\mathrm{W}-\mathrm{Z}(\mathbf{1}-\mathbf{4})$
$\mathrm{C}_{33} \mathrm{H}_{37} \mathrm{NO}_{8} \mathrm{Na}$, 598.2416). The ${ }^{1} \mathrm{H}-\mathrm{NMR}$ spectrum (Table 1) showed the following legible signals: one olefinic proton at $\delta_{\mathrm{H}} 5.34$ (brs), three oxygenated methine protons at $\delta_{\mathrm{H}} 5.77$ (ddd, $J=9.1,6.4,5.4 \mathrm{~Hz}), 5.43(\mathrm{~d}, J=10.0 \mathrm{~Hz})$ and $3.69(\mathrm{dd}$, $J=12.0,10.0 \mathrm{~Hz})$, two AB doublet protons at $\delta_{\mathrm{H}} 4.34$ and 4.24 (each d, $J=9.1 \mathrm{~Hz}$ ) assignable to an oxygenated methylene, and four methyl singlets at $\delta_{\mathrm{H}} 1.67,1.44,1.40$, and 1.10, together with nine characteristic aromatic protons due to one benzoyloxy and one nicotinoyloxy groups. The ${ }^{13} \mathrm{C}-\mathrm{NMR}$ spectrum (Table 1) revealed 20 carbon resonances except for the signals of the forenamed aromatic substitutes, including one ester carbonyl carbon at $\delta_{\mathrm{C}} 174.5$ (s), one trisubstituted double bond at $\delta_{\mathrm{C}} 143.4(\mathrm{~s})$ and $120.4(\mathrm{~d})$, and six oxygenbearing carbons at $\delta_{\mathrm{C}} 82.1(\mathrm{~s}), 79.6(\mathrm{t}), 77.2(\mathrm{~d}), 76.2(\mathrm{~s})$, 74.6 (d) and 71.1 (d). Considering the above NMR character and its biological source, ${ }^{11,13}$ this compound should be a neo-clerodane diterpenoid with a 3-en-13-spiro-15,16- $\gamma$-lactone moiety. The heteronuclear multiple bond coherence (HMBC) correlations (Fig. 2) allowed us to position the benzoyloxy and nicotinoyloxy groups at $\mathrm{C}-1$ and $\mathrm{C}-6$, respectively. On account of almost overlapping $\left(\delta_{\mathrm{C}} 165.66,165.62\right)$ of two aromatic ester carbonyl carbon signals in $\mathrm{CDCl}_{3}$, it is very necessary to change the deuterated solvent $\left(\delta_{\mathrm{C}} 167.2\right.$, 166.1 in $\mathrm{CD}_{3} \mathrm{OD}$ ) for unambiguous assignment of the two aromatic substitutes by HMBC spectrum.

The relative configuration of $\mathbf{1}$ was deduced from its rotating frame Overhauser effect spectroscopy (ROESY) spectrum (Fig. 2). The observable correlations of $\mathrm{H}-7 \leftrightarrow \mathrm{Me}-17$, Me-19 and Me-20; H-1↔Me-19 and Me-20, indicated that these protons were cofacial and $\alpha$-oriented, whereas the correlation of $\mathrm{H}-6 \leftrightarrow \mathrm{H}-10$ was indicative of their $\beta$-orientation. The configuration of $\mathrm{C}-13$ was determined to be $R^{*}$ by the ROESY correlation of Me-17↔H-14a, and the more detailed ROESY information was summarized in Fig. 2. Accordingly, the structure of 1 was elucidated as $\left(13 R^{*}\right)$-1 $\beta$-benzoyloxy$6 \alpha$-nicotinoyloxy-7 $\beta$-hydroxy- $8 \beta, 13$-epoxy-3-neo-cleroden15,16-olide, named scutebarbatine $\mathrm{W}$.

Generally, when no substitution happens in the rings $\mathrm{C}$ and $\mathrm{D}$, there is a reliable and more convenient method to determine the configuration at $\mathrm{C}-13$, which can be achieved just by observation of the diagnostic ${ }^{1} \mathrm{H}$ - and ${ }^{13} \mathrm{C}$-NMR signals in 
Table 1. NMR Data of Carbon-Skeleton Parts of Scutebarbatines $\mathrm{W}-\mathrm{Z}(\mathbf{1}-\mathbf{4})$

\begin{tabular}{|c|c|c|c|c|c|c|c|c|}
\hline \multirow{2}{*}{ No. } & \multicolumn{2}{|r|}{$\mathbf{1}^{a)}$} & \multicolumn{2}{|r|}{$\mathbf{2}^{b)}$} & \multicolumn{2}{|r|}{$\mathbf{3}^{a)}$} & \multicolumn{2}{|r|}{$4^{a)}$} \\
\hline & $\delta_{\mathrm{C}}$ & $\delta_{\mathrm{H}}$ & $\delta_{\mathrm{C}}$ & $\delta_{\mathrm{H}}$ & $\delta_{\mathrm{C}}$ & $\delta_{\mathrm{H}}$ & $\delta_{\mathrm{C}}$ & $\delta_{\mathrm{H}}$ \\
\hline 1 & $71.1(\mathrm{~d})$ & $5.77(\mathrm{ddd}, 9.1,6.4,5.4)$ & $19.9(\mathrm{t})$ & $1.81,2.27(\mathrm{~m})$ & $19.3(\mathrm{t})$ & $1.36,1.66(\mathrm{~m})$ & $17.9(\mathrm{t})$ & $1.58,1.69(\mathrm{~m})$ \\
\hline 2 & $32.7(\mathrm{t})$ & $2.19,2.72(\mathrm{~m})$ & $26.2(\mathrm{t})$ & $2.00,2.17(\mathrm{~m})$ & $26.1(\mathrm{t})$ & $1.96-2.12(\mathrm{~m})$ & $26.3(\mathrm{t})$ & $2.00,2.13(\mathrm{~m})$ \\
\hline 3 & $120.4(d)$ & $5.34(\mathrm{brs})$ & $124.0(\mathrm{~d})$ & $5.24(\mathrm{br} \mathrm{s})$ & $123.1(\mathrm{~d})$ & $5.23(\mathrm{brs})$ & $123.2(\mathrm{~d})$ & $5.25(\mathrm{brs})$ \\
\hline 4 & $143.4(\mathrm{~s})$ & - & $141.5(\mathrm{~s})$ & - & $140.9(\mathrm{~s})$ & - & $141.5(\mathrm{~s})$ & - \\
\hline 5 & $43.8(\mathrm{~s})$ & - & $43.6(\mathrm{~s})$ & - & $43.4(\mathrm{~s})$ & - & $43.4(\mathrm{~s})$ & - \\
\hline 6 & 77.2 (d) & $5.43(\mathrm{~d}, 10.0)$ & 76.9 (d) & $6.32(\mathrm{~d}, 10.1)$ & 75.4 (d) & $5.92(\mathrm{~d}, 10.0)$ & $82.5(\mathrm{~d})$ & $5.03(\mathrm{~d}, 9.6)$ \\
\hline 7 & $74.6(d)$ & $3.69(\mathrm{dd}, 12.0,10.0)$ & $77.5(d)$ & $6.06(\mathrm{~d}, 10.1)$ & 76.7 (d) & $5.73(\mathrm{~d}, 10.0)$ & $73.6(d)$ & $3.65(\mathrm{dd}, 9.6,9.3)$ \\
\hline 8 & $82.1(\mathrm{~s})$ & - & $77.9(\mathrm{~s})$ & - & $76.8(\mathrm{~s})$ & - & 42.7 (d) & $1.61(\mathrm{~m})$ \\
\hline 9 & $38.3(\mathrm{~s})$ & - & $48.2(\mathrm{~s})$ & - & $48.4(\mathrm{~s})$ & - & $39.1(\mathrm{~s})$ & - \\
\hline 10 & $43.5(\mathrm{~d})$ & $2.68(\mathrm{~d}, 9.1)$ & $41.1(\mathrm{~d})$ & $2.71(\mathrm{brd}, 11.9)$ & $42.7(\mathrm{~d})$ & $2.40(\mathrm{brd}, 12.3)$ & $45.3(\mathrm{~d})$ & $1.57(\mathrm{~m})$ \\
\hline 11 & $28.3(\mathrm{t})$ & $1.59,2.05(\mathrm{~m})$ & $76.3(d)$ & $5.99(\mathrm{brd}, 11.0)$ & $147.0(d)$ & $6.42(\mathrm{~d}, 16.9)$ & $35.7(\mathrm{t})$ & $1.63,1.73(\mathrm{~m})$ \\
\hline 12 & $29.4(t)$ & $1.56,2.15(\mathrm{~m})$ & $29.6(t)$ & $\begin{array}{l}3.07(\mathrm{dd}, 14.0,11.0) \\
3.71(\mathrm{brd}, 14.0)\end{array}$ & $121.9(\mathrm{~d})$ & $6.46(d, 16.9)$ & $22.0(\mathrm{t})$ & $2.21,2.31(\mathrm{~m})$ \\
\hline 13 & $76.2(\mathrm{~s})$ & - & $129.7(\mathrm{~s})$ & - & $162.2(\mathrm{~s})$ & - & $170.0(\mathrm{~s})$ & - \\
\hline 14 & $42.2(\mathrm{t})$ & $2.57,2.76($ each d, 17.0) & $140.6(\mathrm{~s})$ & - & $114.9(\mathrm{~d})$ & $5.94($ br s $)$ & $115.4(d)$ & 5.87 (brs) \\
\hline 15 & $174.5(\mathrm{~s})$ & - & $171.1(\mathrm{~s})$ & - & $174.1(\mathrm{~s})$ & - & $173.8(\mathrm{~s})$ & - \\
\hline 16 & $79.6(\mathrm{t})$ & $4.24,4.34$ (each d, 9.1) & $69.6(\mathrm{t})$ & $4.72,5.02$ (each d, 15.9) & $70.7(\mathrm{t})$ & $5.00(\mathrm{brs})$ & $73.0(\mathrm{t})$ & 4.76 (br s) \\
\hline 17 & $20.4(q)^{c)}$ & $1.40(\mathrm{~s})$ & $21.6(q)$ & $1.67(\mathrm{~s})$ & $22.4(\mathrm{q})$ & $1.07(\mathrm{~s})$ & $11.0(\mathrm{q})$ & $1.03(\mathrm{~d}, 6.6)$ \\
\hline 18 & $20.3(\mathrm{q})^{c}$ & 1.67 (brs) & 20.7 (q) & $1.75(\mathrm{brs})$ & $20.1(q)$ & 1.59 (brs) & $20.6(q)$ & $1.57(\mathrm{brs})$ \\
\hline 19 & $16.3(q)$ & $1.44(\mathrm{~s})$ & $17.5(q)$ & $1.50(\mathrm{~s})$ & $17.4(q)$ & $1.45(\mathrm{~s})$ & $17.6(q)$ & $1.34(\mathrm{~s})$ \\
\hline 20 & $21.4(q)$ & $1.10(\mathrm{~s})$ & $16.5(q)$ & $1.10(\mathrm{~s})$ & $15.4(q)$ & $1.28(\mathrm{~s})$ & $18.9(q)$ & $0.89(\mathrm{~s})$ \\
\hline $7-\mathrm{OH}$ & & $2.07(\mathrm{~d}, 12.0)$ & & & & & & $1.78(\mathrm{brs})$ \\
\hline $8-\mathrm{OH}$ & & & & 7.34 (brs) & & $2.79(\mathrm{br} \mathrm{s})$ & & \\
\hline $14-\mathrm{OH}$ & & & & 12.82 (brs) & & & & \\
\hline
\end{tabular}

$a, b)$ Measured in $\mathrm{CDCl}_{3}\left(\delta_{\mathrm{H}} 7.26, \delta_{\mathrm{C}} 77.0 \mathrm{ppm}\right)$ and pyridine- $d_{5}\left(\delta_{\mathrm{H}} 8.71, \delta_{\mathrm{C}} 149.9 \mathrm{ppm}\right)$, respectively. $\left.c\right)$ Interchangeable.
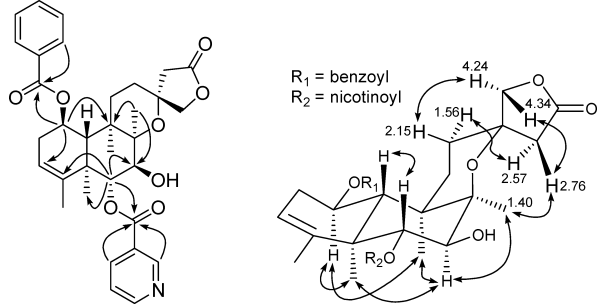

Fig. 2. Significant HMBC and ROESY Correlations of $\mathbf{1}$

$\mathrm{CDCl}_{3}$. Presence of the signals around at $\delta_{\mathrm{H}} 2.57,2.76$ (each $\mathrm{d}, \mathrm{H}-14, \Delta \approx 0.20 \mathrm{ppm})$ and at $\delta_{\mathrm{C}} 42.2$ (t, C-14), 79.6 (t, C$16)$ is indicative of a $13 R^{*}$ form, while a $13 S^{*}$ analogue will display a set of signals at 2.60, 3.15 (each d, H-14, $\Delta \approx 0.55 \mathrm{ppm}$ ) and at $\delta_{\mathrm{C}} 44.3$ (t, C-14), 76.4 (t, C-16). The rule can efficaciously assign the configuration at $\mathrm{C}-13$ of this subtype of neo-clerodanes. By chance, scutebarbatine W (1) was found to be contaminated by a trace amount of the C-13 epimer ( $13 S^{*}$ form) in our current study, in addition, more minor C-13 epimers can be also detectable in the NMR spectra (see supporting information in ref. 13) of scutebatas D, E and $\mathrm{F}$.

Recently, Dai and co-workers uninterruptedly reported many new neo-clerodanes from the same plant. ${ }^{3-10,14)}$ However, the authors proposed a series of wrong structures because of failure to comprehend NMR information, especially the application of HMBC correlations and the calculation of coupling constants. Now scutehenanine B $(\mathbf{5})^{10)}$ is chosen to discuss its structure revision. Compound $\mathbf{5}$ is found to be identical with $\mathbf{1}$, and the conclusion is based on the following forceful evidence or reasons: 1) the NMR data (see supporting information in ref. 10) are in complete accord with those of $1 ; 2$ ) the authors did not accurately handle the HMBC and ROESY correlations, and did not know how to calculate coupling constants of complex signals, for example, the proton signal at $\delta_{\mathrm{H}} 5.77$ is a legible ddd coupling and not so-called double doublet with $J=12.2,3.5 \mathrm{~Hz} ; 3$ ) because of almost overlapping of two aromatic ester carbonyl carbons in $\mathrm{CDCl}_{3}$, the ester carbonyl signal of the benzoyloxy group can not be observed at $\delta_{\mathrm{C}} 165.9$ and was imaginary. According to the above discussion and combining the reported NMR data, the nicotinoyloxy group at $\mathrm{C}-11$ and the spirocarbon configuration of scutebarbatine $\left.\mathrm{G}(6)^{5}\right)$ and 6-O-nicotinoylscutebarbatine $\mathrm{G}(7)^{9)}$ should be adjusted to at $\mathrm{C}-1$ and as $13 R^{*}$ form, respectively. Similarly, the substitute at C-11 in barbatin A (8), ${ }^{4}$ 6,7-di- $O$-nicotinoylscutebarbatine $\mathrm{G}(9)^{5)}$ and $6-O$ nicotinoyl-7- $O$-acetylscutebarbatine $\mathrm{G}(\mathbf{1 0})^{5)}$ should be all repositioned at $\mathrm{C}-1$, and the original assignment of scutebarbatine $\mathrm{F}(\mathbf{1 1})^{3)}$ is more unimaginable and should be revised as shown in Fig. 3. Among them, 6-O-nicotinoyl-7-O-acetylscutebarbatine G (10) and scutebarbatine F (11) are actually identical with subsequently reported barbatine $\mathrm{D}^{11)}$ and barbatine $\mathrm{C}^{11)}$ (=scutebata $\left.\mathrm{F}\right){ }^{13)}$ respectively. The structural revision of 5-11 has been summarized in Fig. 3.

Scutebarbatine $\mathrm{X}$ (2), obtained as amorphous powder, had the molecular formula $\mathrm{C}_{34} \mathrm{H}_{38} \mathrm{~N}_{2} \mathrm{O}_{10}$ according to its positive HR-ESI-MS at $m / z 657.2425$ (Calcd for $\mathrm{C}_{34} \mathrm{H}_{38} \mathrm{~N}_{2} \mathrm{O}_{10} \mathrm{Na}$, 657.2424). The ${ }^{1} \mathrm{H}$ - and ${ }^{13} \mathrm{C}-\mathrm{NMR}$ spectra (Table 1 ) bearing two nicotinoyloxy and one acetoxy groups were very similar to those of scutebatas $\mathrm{A}$ and $\mathrm{B},{ }^{13)}$ which suggested that $\mathbf{2}$ was a 6,7,8,11,14-pentaoxygenated 3,13-neo-clerodadien-15,16olide derivative. The HMBC correlations allowed us to position the two nicotinoyloxy and one acetoxy groups at C-6, C7 and $\mathrm{C}-11$, respectively. By comparing the ROESY spectrum with reported, the relative configuration of C-6, C-7 and 

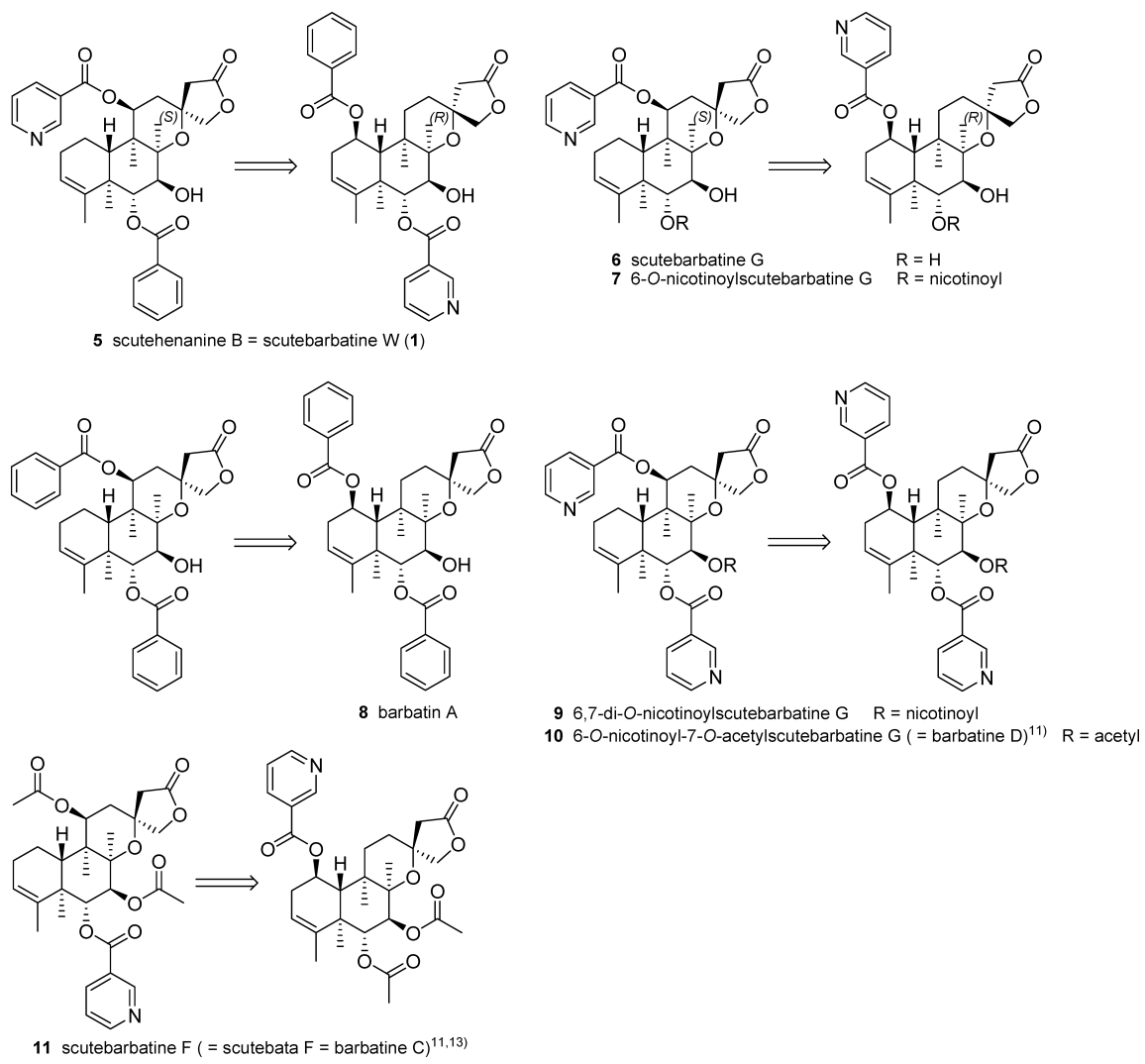

10 6-O-nicotinoyl-7-O-acetylscutebarbatine $\mathrm{G}$ ( = barbatine $\mathrm{D})^{11)} \mathrm{R}=$ acetyl

Fig. 3. Structure Revision of 5-11

C-11 was found to be the same as those of scutebatas A and B. Therefore, the structure of 2 was determined as $\left(11 S^{*}\right)$ $6 \alpha, 7 \beta$-dinicotinoyloxy-8 $\beta, 14$-dihydroxy-11-acetoxy-3,13neo-clerodadien-15,16-olide.

Scutebarbatine Y (3) was also obtained as amorphous powder. Its molecular formula was determined to be $\mathrm{C}_{33} \mathrm{H}_{35} \mathrm{NO}_{7}$ on the basis of the positive HR-ESI-MS at $\mathrm{m} / \mathrm{z}$ 580.2298 (Calcd for $\mathrm{C}_{33} \mathrm{H}_{35} \mathrm{NO}_{7} \mathrm{Na}, 580.2311$ ). The ${ }^{1} \mathrm{H}-\mathrm{NMR}$ spectrum (Table 1) showed the following clear signals: four olefinic protons at $\delta_{\mathrm{H}} 6.46,6.42$ (each d, $J=16.9 \mathrm{~Hz}$ ), 5.94 (brs) and $5.23(\mathrm{brs})$, a pair of intercoupling protons at $\delta_{\mathrm{H}}$ $5.92(\mathrm{~d}, J=10.0 \mathrm{~Hz})$ and $5.73(\mathrm{~d}, J=10.0 \mathrm{~Hz})$, two protons at $\delta_{\mathrm{H}} 5.00(2 \mathrm{H}, \mathrm{s})$ assignable to an oxygenated methylene, as well as four methyl singlets at $\delta_{\mathrm{H}} 1.59(\mathrm{br} \mathrm{s}), 1.45,1.28$ and 1.07. The ${ }^{1} \mathrm{H}$ - and ${ }^{13} \mathrm{C}$-NMR data (Table 1 ) were very similar to those of scutebarbatine $\mathrm{A}^{2,11)}$ nevertheless a set of newly arisen benzoyloxy signals displaced the resonances of a nicotinoyloxy group in scutebarbatine A. The HMBC correlations from the proton at $\delta_{\mathrm{H}} 5.92(1 \mathrm{H}, \mathrm{d}, J=10.0 \mathrm{~Hz}, \mathrm{H}-6)$ to the carbons at $\delta_{\mathrm{C}} 140.9$ (s, C-4), 17.4 (q, C-19) and $166.0(\mathrm{~s})$, and from the protons at $\delta_{\mathrm{H}} 7.78(2 \mathrm{H}, \mathrm{d}, J=8.2 \mathrm{~Hz})$ to the carbon at $\delta_{\mathrm{C}} 166.0(\mathrm{~s})$, were observed, therefore the newly arisen benzoyloxy group was assigned to C- 6 . The relative configuration of $\mathbf{3}$ was deduced to be the same as those of scutebarbatines A and B based on their accordant NMR data (including coupling constants) and similar optical rotation behavior. ${ }^{2,4,11)}$ Thus the structure of $\mathbf{3}$ was established as $6 \alpha$ benzoyloxy-7 $\beta$-nicotinoyloxy-8 $\beta$-hydroxy-3,11(E),13-neoclerodatrien-15,16-olide.

Scutebarbatine Z (4), amorphous powder, possessed the molecular formula $\mathrm{C}_{26} \mathrm{H}_{33} \mathrm{NO}_{5}$, determined by the positive
HR-ESI-MS at $\mathrm{m} / \mathrm{z} 462.2263$ (Calcd for $\mathrm{C}_{26} \mathrm{H}_{33} \mathrm{NO}_{5} \mathrm{Na}$, 462.2256). The ${ }^{1} \mathrm{H}-\mathrm{NMR}$ spectrum (Table 1) displayed two olefinic protons at $\delta_{\mathrm{H}} 5.87(\mathrm{brs})$ and $5.25(\mathrm{brs})$, two oxygenated methine protons at $\delta_{\mathrm{H}} 5.03(\mathrm{~d}, J=9.6 \mathrm{~Hz})$ and 3.65 (dd, $J=9.6,9.3 \mathrm{~Hz})$, two protons at $\delta_{\mathrm{H}} 4.76(2 \mathrm{H}, \mathrm{s})$ assignable to an oxygenated methylene, four methyl signals at $\delta_{\mathrm{H}}$ $1.57(\mathrm{br} \mathrm{s}), 1.34(\mathrm{~s}), 1.03(\mathrm{~d}, J=6.6 \mathrm{~Hz})$ and $0.89(\mathrm{~s})$, as well as a set of characteristic nicotinoyloxy protons. The ${ }^{13} \mathrm{C}$ NMR spectrum (Table 1) revealed 20 carbon resonances except for a set of nicotinoyloxy signals, including one ester carbonyl carbon at $\delta_{\mathrm{C}} 173.8(\mathrm{~s})$, four olefinic carbons at $\delta_{\mathrm{C}}$ $170.0(\mathrm{~s}), 141.5(\mathrm{~s}), 123.2$ (d) and 115.4 (d), and three oxygen-bearing carbons at $\delta_{\mathrm{C}} 82.5(\mathrm{~d}), 73.6(\mathrm{~d})$ and $73.0(\mathrm{t})$. The above NMR character allowed us to make a conclusion that this compound was a 6,7-dioxygenated 3,13-neo-clerodadien-15,16-olide derivative. The strong HMBC correlations from the proton at $\delta_{\mathrm{H}} 5.03(1 \mathrm{H}, \mathrm{d}, J=9.6 \mathrm{~Hz}, \mathrm{H}-6)$ to the carbons at $\delta_{\mathrm{C}} 141.5$ (s, C-4), $17.6(\mathrm{q}, \mathrm{C}-19)$ and 166.3 (s) indicated that the nicotinoyloxy group was located at C-6. The relative configuration of $\mathrm{C}-6$ and $\mathrm{C}-7$ was in accordance with those of $\mathbf{1}-\mathbf{3}$ based on the similarity of their $\mathrm{H}-6 / \mathrm{H}-7$ coupling constants. As a result, the structure of 4 was determined as $6 \alpha$-nicotinoyloxy-7 $\beta$-hydroxy-3,13-neo-clerodadien-15,16-olide.

\section{Experimental}

General Experimental Procedures Optical rotations were measured on a Jasco P-1020 (Jasco International Co., Ltd., Tokyo, Japan) automatic digital polarimeter. IR spectra were recorded using a Bruker Tensor 27 FT-IR (Bruker Optics GmbH, Ettlingen, Germany) spectrometer with $\mathrm{KBr}$ pellets. UV data were obtained from online HPLC analysis. NMR spectra were carried out on either a Bruker DRX-500 or AV-400 (Bruker BioSpin GmbH, 
Rheinstetten, Germany) spectrometer with the deuterated solvent as an internal standard. ESI-MS (including HR-ESI-MS) were measured on an API QSTAR Pulsar i (MDS Sciex, Concord, Ontario, Canada) mass spectrometer. Silica gel 200-300 mesh (Qingdao Marine Chemical Inc., Qingdao, China), Sephadex LH-20 (Amersham Biosciences, Uppsala, Sweden), Chromatorex MB C18 (40-75 $\mu \mathrm{m}$, Fuji Silysia Chemical Ltd., Kasugai, Aichi, Japan) and MCI gel CHP 20P (75-150 $\mu \mathrm{m}$, Mitsubishi Chemical Corp., Tokyo, Japan) were used for normal pressure column chromatography. Fractions were monitored and analyzed by TLC (Qingdao Marine Chemical Inc., China), in combination with Agilent 1200 series HPLC system (Eclipse XDB-C18 column, $5 \mu \mathrm{m}, 4.6 \times 150 \mathrm{~mm}$ ).

Plant Material The whole plants of S. barbata were collected in Xinping County of Yunnan Province, China, in March 2008, and identified by Mr. Yu Chen of Kunming Institute of Botany, CAS. A voucher specimen (No. BBP2010010SB) was deposited at BioBioPha.

Extraction and Isolation Dried and powdered whole plants $(9.5 \mathrm{~kg})$ of S. barbata were extracted with $95 \%$ ethanol at room temperature. The alcohol extract was concentrated to give a residue $(c a .1 .0 \mathrm{~kg})$, which was fractionalized by silica gel column chromatography eluted with a solvent system of petroleum ether (PE)/acetone $(20: 1,10: 1,6: 1,3: 1,1: 1,0: 1)$ and then pure methanol to yield fractions $\mathrm{A}-\mathrm{G}$, respectively. Fraction $\mathrm{D}$ eluted by $25 \%$ acetone was separated on silica gel using a solvent system of $\mathrm{CHCl}_{3} / \mathrm{MeOH}(50: 1,20: 1)$ to obtain subfractions I and II, respectively. Subfraction I was further isolated and purified by silica gel, Sephadex LH$20\left(\mathrm{CHCl}_{3} / \mathrm{MeOH}, 1: 1\right), \mathrm{C} 18(40 \rightarrow 75 \% \mathrm{MeOH}$ in water $), \mathrm{MCI}(60 \rightarrow 100 \%$ $\mathrm{MeOH}$ in water) columns and recrystallization to afford $\mathbf{4}(3.0 \mathrm{mg})$ and 3 $(10 \mathrm{mg})$, and compound 1 (47 mg) was obtained from subfraction II in the same way. Fraction E eluted by $50 \%$ acetone was repeatedly isolated and purified by silica gel, MCI $(60 \rightarrow 100 \% \mathrm{MeOH}$ in water) and Sephadex LH-20 $\left(\mathrm{CHCl}_{3} / \mathrm{MeOH}, 1: 1\right)$ columns to afford $2(142 \mathrm{mg})$. The retention times $\left(t_{\mathrm{R}}\right)$ of $\mathbf{1}-\mathbf{4}$ from analysis-type $\mathrm{HPLC}\left(50 \rightarrow 100 \% \mathrm{MeOH}\right.$ in $\mathrm{H}_{2} \mathrm{O}$ over 6 min followed by $100 \% \mathrm{MeOH}$ to $10 \mathrm{~min}, 1 \mathrm{ml} / \mathrm{min}, 20^{\circ} \mathrm{C}$ ) were $7.3,6.6,7.7$ and $6.7 \mathrm{~min}$, respectively.

Scutebarbatine W (1): Colorless powder, $[\alpha]_{\mathrm{D}}^{19}-55.9^{\circ}(c=0.24, \mathrm{MeOH})$. UV $\lambda_{\max }(\mathrm{MeOH}): 226,263 \mathrm{~nm}$. IR $(\mathrm{KBr}): 3431,1782,1712,1637,1279$, $1109,1037 \mathrm{~cm}^{-1}$. NMR data of the carbon-skeleton part: see Table $1 . \mathrm{NMR}$ data $\left(\mathrm{CDCl}_{3}\right)$ of the substitute groups: 1-benzoyloxy, $\delta_{\mathrm{H}} 7.97(2 \mathrm{H}, \mathrm{d}$, $J=7.8 \mathrm{~Hz}), 7.60(1 \mathrm{H}, \mathrm{t}, J=7.8 \mathrm{~Hz}), 7.47(2 \mathrm{H}, \mathrm{t}, J=7.8 \mathrm{~Hz}), \delta_{\mathrm{C}} 165.66$ or 165.62 (s) [167.2 ppm in $\left.\mathrm{CD}_{3} \mathrm{OD}\right], 133.4$ (d), 130.0 (s), $129.4(2 \times \mathrm{d}), 128.6$ $(2 \times \mathrm{d})$; 6-nicotinoyloxy, $\delta_{\mathrm{H}} 9.26(1 \mathrm{H}$, br d, $J=1.8 \mathrm{~Hz}), 8.79(1 \mathrm{H}, \mathrm{dd}, J=4.9$, $1.8 \mathrm{~Hz}), 8.32(1 \mathrm{H}$, ddd, $J=7.8,1.8,1.8 \mathrm{~Hz}), 7.42(1 \mathrm{H}$, br dd, $J=7.8,4.9 \mathrm{~Hz})$, $\delta_{\mathrm{C}} 165.62$ or 165.66 (s) [166.1 ppm in $\mathrm{CD}_{3} \mathrm{OD}$ ], 153.5 (d), 150.9 (d), 137.2 (d), 126.4 (s), 123.4 (d). ESI-MS (pos.): 598 [M+Na] ${ }^{+}$. HR-ESI-MS (pos.): 598.2426 (Calcd for $\mathrm{C}_{33} \mathrm{H}_{37} \mathrm{NO}_{8} \mathrm{Na}, 598.2416$ ).

Scutebarbatine X (2): Colorless powder, $[\alpha]_{\mathrm{D}}^{23}-50.8^{\circ}(c=0.18, \mathrm{MeOH})$. UV $\lambda_{\max }(\mathrm{MeOH}): 223,264$ (sh), 272 (sh) nm. IR (KBr): 3484, 1763, 1730, $1590,1289,1112,1020 \mathrm{~cm}^{-1}$. NMR data of the carbon-skeleton part: see Table 1. NMR data $\left(\mathrm{C}_{5} \mathrm{D}_{5} \mathrm{~N}\right)$ of the substitute groups: 6-nicotinoyloxy, $\delta_{\mathrm{H}}$ $9.36(1 \mathrm{H}$, brd, $J=1.8 \mathrm{~Hz}), 8.70(1 \mathrm{H}, \mathrm{dd}, J=4.9,1.8 \mathrm{~Hz}), 8.22(1 \mathrm{H}$, ddd, $J=7.9,1.8,1.8 \mathrm{~Hz}), 7.19(1 \mathrm{H}$, br dd, $J=7.9,4.9 \mathrm{~Hz}), \delta_{\mathrm{C}} 165.5(\mathrm{~s}), 154.0(\mathrm{~d})$, $151.0(\mathrm{~d}), 137.0$ (d), 126.5 (s), 123.8 (d); 7-nicotinoyloxy, $\delta_{\mathrm{H}} 9.26(1 \mathrm{H}$, br d, $J=1.8 \mathrm{~Hz}), 8.64(1 \mathrm{H}, \mathrm{dd}, J=4.9,1.8 \mathrm{~Hz}), 8.09(1 \mathrm{H}, \mathrm{ddd}, J=7.9,1.8,1.8 \mathrm{~Hz})$, $7.04(1 \mathrm{H}$, br dd, $J=7.9,4.9 \mathrm{~Hz}), \delta_{\mathrm{C}} 165.7$ (s), 154.2 (d), 151.3 (d), 137.2 (d), $125.6(\mathrm{~s}), 123.4(\mathrm{~d}) ; 11$-acetoxy, $\delta_{\mathrm{H}} 2.15(3 \mathrm{H}, \mathrm{s}), \delta_{\mathrm{C}} 171.4(\mathrm{~s}), 21.0(\mathrm{q})$. ESIMS (pos.): $657[\mathrm{M}+\mathrm{Na}]^{+}$. HR-ESI-MS (pos.): 657.2425 (Calcd for $\left.\mathrm{C}_{34} \mathrm{H}_{38} \mathrm{~N}_{2} \mathrm{O}_{10} \mathrm{Na}, 657.2424\right)$.

Scutebarbatine Y (3): Colorless powder, $[\alpha]_{\mathrm{D}}^{25}-104.7^{\circ}(c=0.10, \mathrm{MeOH})$. UV $\lambda_{\max }(\mathrm{MeOH}): 223(\mathrm{sh}), 259 \mathrm{~nm}$. IR (KBr): 3426, 1781, 1745, 1726, $1643,1594,1451,1285,1113,1028 \mathrm{~cm}^{-1}$. NMR data of the carbon-skeleton part: see Table 1 . NMR data $\left(\mathrm{CDCl}_{3}\right)$ of the substitute groups: 6-benzoyloxy, $\delta_{\mathrm{H}} 7.78(2 \mathrm{H}, \mathrm{d}, J=8.2 \mathrm{~Hz}), 7.41(1 \mathrm{H}, \mathrm{t}, J=7.3 \mathrm{~Hz}), 7.26(2 \mathrm{H}, \mathrm{dd}, J=8.2$, $7.3 \mathrm{~Hz}), \delta_{\mathrm{C}} 166.0(\mathrm{~s}), 133.1(\mathrm{~d}), 129.8(\mathrm{~s}), 129.3(2 \times \mathrm{d}), 128.3(2 \times \mathrm{d}) ; 7-$ nicotinoyloxy, $\delta_{\mathrm{H}} 9.00(1 \mathrm{H}$, brd, $J=1.8 \mathrm{~Hz}), 8.63(1 \mathrm{H}, \mathrm{dd}, J=4.9,1.8 \mathrm{~Hz})$, $8.08(1 \mathrm{H}$, ddd, $J=7.8,1.8,1.8 \mathrm{~Hz}), 7.21(1 \mathrm{H}$, br dd, $J=7.8,4.9 \mathrm{~Hz}), \delta_{\mathrm{C}} 164.8$ (s), 153.4 (d), 150.9 (d), 137.2 (d), 124.9 (s), 123.0 (d). ESI-MS (pos.): 580 $[\mathrm{M}+\mathrm{Na}]^{+}$. HR-ESI-MS (pos.): 580.2298 (Calcd for $\mathrm{C}_{33} \mathrm{H}_{35} \mathrm{NO}_{7} \mathrm{Na}$, 580.2311).

Scutebarbatine Z (4): Colorless powder, $[\alpha]_{\mathrm{D}}^{25}-26.5^{\circ}(c=0.10, \mathrm{MeOH})$. UV $\lambda_{\max }(\mathrm{MeOH}): 214,257$ (sh), 263, $272(\mathrm{sh}) \mathrm{nm}$. IR (KBr): 3426, 1784, $1753,1717,1636,1597,1282,1112,1029 \mathrm{~cm}^{-1}$. NMR data of the carbonskeleton part: see Table 1. NMR data $\left(\mathrm{CDCl}_{3}\right)$ of the substitute group: 6nicotinoyloxy, $\delta_{\mathrm{H}} 9.28(1 \mathrm{H}$, br s), $8.79(1 \mathrm{H}$, brd, $J=4.9 \mathrm{~Hz}), 8.34(1 \mathrm{H}$, br d, $J=7.8 \mathrm{~Hz}), 7.42(1 \mathrm{H}$, br dd, $J=7.8,4.9 \mathrm{~Hz}), \delta_{\mathrm{C}} 166.3$ (s), 153.6 (d), 151.0 (d), 137.3 (d), 126.5 (s), 123.4 (d). ESI-MS (pos.): $462[\mathrm{M}+\mathrm{Na}]^{+}$. HR-ESIMS (pos.): 462.2263 (Calcd for $\mathrm{C}_{26} \mathrm{H}_{33} \mathrm{NO}_{5} \mathrm{Na}, 462.2256$ ).

Acknowledgements This work was financially supported by National Basic Research Program of China (973 Program) 2009CB522300 and the R\&D funds from BioBioPha.

\section{References}

1) Gebbinck E. A. K., Jansen B. J. M., de Groot A., Phytochemistry, 61, $737-770$ (2002).

2) Wang Z. Q., Xu F. M., Yan X. Z., Zhu Y., Chin. Chem. Lett., 7, 333334 (1996).

3) Dai S. J., Chen M., Liu K., Jiang Y. T., Shen L., Chem. Pharm. Bull., 54, 869-872 (2006).

4) Dai S. J., Tao J. Y., Liu K., Jiang Y. T., Shen L., Phytochemistry, 67, 1326-1330 (2006).

5) Dai S. J., Wang G. F., Chen M., Liu K., Shen L., Chem. Pharm. Bull., 55, 1218-1221 (2007).

6) Dai S. J., Sun J. Y., Ren Y., Liu K., Shen L., Planta Med., 73, 1217 1220 (2007).

7) Dai S. J., Liang D. D., Ren Y., Liu K., Shen L., Chem. Pharm. Bull., 56, 207-209 (2008).

8) Dai S. J., Shen L., Ren Y., J. Integr. Plant Biol., 50, 699-702 (2008).

9) Dai S. J., Peng W. B., Shen L., Zhang D. W., Ren Y., J. Asian Nat. Prod. Res., 11, 451-456 (2009).

10) Dai S. J., Peng W. B., Zhang D. W., Shen L., Wang W. Y., Ren Y., J. Nat. Prod., 72, 1793-1797 (2009).

11) Nguyen V. H., Pham V. C., Nguyen T. T. H., Tran V. H., Doan T. M. H., Eur. J. Org. Chem., 2009, 5810-5815 (2009).

12) Lee H., Kim Y. J., Choi I., Min B. S., Shim S. H., Bioorg. Med. Chem. Lett., 20, 288-290 (2010).

13) Zhu F., Di Y. T., Liu L. L., Zhang Q., Fang X., Yang T. Q., Hao X. J., He H. P., J. Nat. Prod., 73, 233-236 (2010).

14) Dai S. J., Qu G. W., Yu Q. Y., Zhang D. W., Li G. S., Fitoterapia, 81, in press (2010). (doi: 10.1016/j.fitote.2010.01.001)

15) Wang F., Xie Z. H., Gao Y., Xu Y., Cheng X. L., Liu J. K., Chem. Pharm. Bull., 56, 864-865 (2008).

16) Wang F., Li X. M., Liu J. K., Chem. Pharm. Bull., 57, 525-527 (2009).

17) Wang F., Ren F. C., Liu J. K., Phytochemistry, 70, 650 -654 (2009).

18) Wang F., Cheng X. L., Li Y. J., Shi S., Liu J. K., J. Nat. Prod., 72, 2005-2008 (2009).

19) Wang F., Gao Y., Zhang L., Liu J. K., Org. Lett., 12, 2354-2357 (2010). 